\title{
Caries prevention guidelines
}

\author{
Derek Richards \\ Editor, Evidence-based Dentistry
}

Evidence-Based Dentistry (2008) 9, 66. doi: 10.1038/sj.ebd.6400590

In this issue, we summarise the latest evidence-based clinical recommendations from the American Dental Association on the use of pit and fissure sealants. ${ }^{1}$ Sealants have been available since the 1960s and, although many studies have found that they are effective in reducing decay, it was not until 1993 that the first systematic review was conducted by Llodra and colleagues. ${ }^{2}$ Since then, there have been two further Cochrane reviews ${ }^{3,4}$ focussing on caries prevention using sealants and one by Griffin et $a .^{5}$ assessing their effectiveness in the management of caries.

Despite clear evidence of effectiveness - the review by Ahovuo-Saloranta et al. ${ }^{4}$ shows a reduction in decay of $86 \%$ in children's permanent teeth at 12 months - their rate of adoption seems rather slow. Will this new guideline help?

Although the evidence is robust, there seems little likelihood that it will lead to a large increase in uptake in the UK. There have already been two sets of guidelines published by the Scottish Intercollegiate Guidelines Network ${ }^{6,7}$ and other publications ${ }^{8,9}$ extolling evidence-based approaches to prevention of dental disease. Despite the admirable intentions of the funders and developers of these guidelines, there is far less planning of the dissemination and implementation of these guidelines. With a stubbornly large proportion of the child population of the UK still suffering from caries, ${ }^{10}$ should we not be doing more to identify the barriers and improve the uptake of these relatively simple preventive treatments?

Systematic reviews have examined the effectiveness and efficiency of guideline dissemination and implementation, ${ }^{11}$ but there remains an imperfect evidence base to support decisions about which strategies are likely to work in different circumstances. The majority of studies undertaken so far have been in the medical sector: precious few have been undertaken in dentistry. An exception, however, is a recent report by Clarkson et al., ${ }^{12}$ looking at interventions to improve the rate of sealant use in Scotland, where fewer than $20 \%$ of 11 -year-olds have their first molars sealed. ${ }^{13}$ The study tested the use of an additional fee, compared with education or both interventions, compared with a no-intervention control. The fee intervention was the most effective and statistically significant, but only two-thirds of those eligible claimed the fee. The authors suggest that the possible reasons for the modest impact of the intervention were either that the children were not seen as being at risk of caries, their teeth had already been filled, or too much additional effort was required to claim the fee from the research team. The education group also showed a positive trend.

In a previous Editorial, ${ }^{14}$ I highlighted "the killer Bs" which are worth recalling in relation to this new sealant guideline:

- Burden. Is the burden of illness or frequency in our community too low to warrant implementation?

- Beliefs. Are the beliefs of held by individual patients or communities about the value of the interventions or their consequences inherently incompatible with the guideline?

- Bargain. Would the opportunity costs of implementing this guideline constitute a bad bargain in the use of our energy or our communities' resources?

- Barriers. Are the barriers (geographical, organisational, traditional, authoritarian, legal or behavioural) so high that it is not worth trying to overcome them?

I believe that the answer to all these questions is no, in relation to the use of sealants and the recent evidence-based prevention guidelines: we should be adopting them enthusiastically.
1. Beauchamp J, Caufield PW, Crall J], et al. Evidencebased clinical recommendations for the use of pitand-fissure sealants: a report of the American Dental Association Council on Scientific Affairs. J Am Dent Assoc 2008; 139:257-268.

2. Llodra J, Bravo M, Delgado-Rodriquez M, Baca P, Galvez R. Factors influencing the effectiveness of sealants: a meta-analysis. Community Dentistry Oral Epidemiol 1993; 21:261-268.

3. Hiiri A, Ahovuo-Saloranta A, Nordblad A, Mäkelä $M$. Pit and fissure sealants versus fluoride varnishes for preventing dental decay in children and adolescents. Cochrane Database Syst Rev 2006; issue 4.

4. Ahovuo-Saloranta A, Hiiri A, Nordblad A, Worthington $\mathrm{H}$, Mäkelä M. Pit and fissure sealants for preventing dental decay in the permanent teeth of children and adolescents. Cochrane Database Syst Rev 2004; issue 3.

5. Griffin SO, Oong E, Kohn W, et al. The effectiveness of sealants in managing caries lesions. J Dent Res 2008; 87:169-174.

6. Scottish Intercollegiate Guidelines Network. Preventing Dental Caries in Children at High Caries Risk: Targeted Prevention of Dental Caries in the Permanent Teeth of 6-16 Year Olds Presenting for Dental Care. National Clinical Guideline no. 47. Edinburgh: Scottish Intercollegiate Guidelines Network; 2000.

7. Scottish Intercollegiate Guidelines Network. Prevention and Management of Dental Decay in the Pre-school Child. National Clinical Guideline no. 83. Edinburgh: Scottish Intercollegiate Guidelines Network; 2005.

8. American Dental Association Council on Scientific Affairs. Professionally applied topical fluoride: evidence-based clinical recommendations. J Dent Educ 2007; 71:393-402.

9. Department of Health/British Association for the Study of Community Dentistry. Delivering Better Oral Health: an Evidence-based Toolkit for Prevention. London: Department of Health; 2007.

10. Pitts NB, Chestnutt IG, Evans D, White D, Chadwick B, Steele JG. The dentinal caries experience of children in the United Kingdom, 2003. Br Dent J 2006; 200:313-320.

11. Grimshaw JM, Thomas RE, MacLennan G, et al. Effectiveness and efficiency of guideline dissemination and implementation strategies. Health Technol Assess 2004; 8:1-72.

12. Clarkson JE, Turner S, Grimshaw JM, et al. Changing clinicians' behavior: a randomized controlled trial of fees and education. J Dent Res 2008; 87:640-644.

13. Merrett MCW, Goold S, Jones CM, et al. National Dental Inspection Programme of Scotland: Report of the 2007 Survey of P7 Children. Edinburgh: Scottish Dental Epidemiological Co-ordinating Committee; 2008.

14. Richards D. Guidelines and the killer Bs. Evid based Dent 2006; 7:1-2. 